University of Nebraska - Lincoln

DigitalCommons@University of Nebraska - Lincoln

Publications from USDA-ARS / UNL Faculty

U.S. Department of Agriculture: Agricultural

Research Service, Lincoln, Nebraska

8-27-2007

\title{
Cloning and expression of an atrazine inducible cytochrome P450, CYP4G33, from Chironomus tentans (Diptera: Chironomidae)
}

\author{
Diana K. Londono \\ University of Nebraska-Lincoln \\ Herbert A.A. Siqueira \\ Universidade Federal Rural de Pernambuco, Departamento de Agronomia-Entomologia, 52171-900 \\ Recife-PE, Brazil \\ Haichuan Wang \\ University of Nebraska-Lincoln, hwang4@unl.edu \\ Gautam Sarath \\ University of Nebraska-Lincoln, Gautam.sarath@ars.usda.gov \\ Michael J. Lydy \\ Southern Illinois University, mlydy@siu.edu \\ See next page for additional authors
}

Follow this and additional works at: https://digitalcommons.unl.edu/usdaarsfacpub

Part of the Agricultural Science Commons

Londono, Diana K.; Siqueira, Herbert A.A.; Wang, Haichuan; Sarath, Gautam; Lydy, Michael J.; and Siegfried, Blair D., "Cloning and expression of an atrazine inducible cytochrome P450, CYP4G33, from Chironomus tentans (Diptera: Chironomidae)" (2007). Publications from USDA-ARS / UNL Faculty. 44. https://digitalcommons.unl.edu/usdaarsfacpub/44

This Article is brought to you for free and open access by the U.S. Department of Agriculture: Agricultural Research Service, Lincoln, Nebraska at DigitalCommons@University of Nebraska - Lincoln. It has been accepted for inclusion in Publications from USDA-ARS / UNL Faculty by an authorized administrator of DigitalCommons@University of Nebraska - Lincoln. 


\section{Authors}

Diana K. Londono, Herbert A.A. Siqueira, Haichuan Wang, Gautam Sarath, Michael J. Lydy, and Blair D. Siegfried 


\title{
Cloning and expression of an atrazine inducible cytochrome P450, CYP4G33, from Chironomus tentans (Diptera: Chironomidae)
}

\author{
Diana K. Londoño ${ }^{\text {a }}$, Herbert A.A. Siqueira ${ }^{\text {b }}$, Haichuan Wang ${ }^{\text {a }}$, Gautam Sarath ${ }^{\text {c }}$, \\ Michael J. Lydy ${ }^{\text {, }}$, Blair D. Siegfried ${ }^{\text {a,* }}$ \\ ${ }^{a}$ Department of Entomology, University of Nebraska-Lincoln, 202 Plant Industry Building, Lincoln, NE 68583, USA \\ ${ }^{\mathrm{b}}$ Universidade Federal Rural de Pernambuco, Departamento de Agronomia-Entomologia, 52171-900 Recife-PE, Brazil \\ ${ }^{\mathrm{c}}$ USDA-ARS Grain, Forage \& Bioenergy Research, Lincoln, NE 68583, USA \\ d Department of Zoology, Fisheries and Illinois Aquaculture Center, Southern Illinois University, Carbondale, IL 62901, USA
}

Received 8 February 2007; accepted 11 April 2007

Available online 19 April 2007

\begin{abstract}
Previous studies performed in our laboratory have measured the effect of atrazine exposure on cytochrome P450-dependent monooxygenase activity and have found increased activity in midge larvae (Chironomus tentans) as a result of atrazine exposure (1$10 \mathrm{ppm})$. Here we report the cloning and expression of a specific $C$. tentans CYP4 gene that is responsive to atrazine induction with an open reading frame of $1678 \mathrm{bp}$ which encodes a putative protein of 559 amino acid residues. Alignments of deduced amino acid sequences with other insect P450 genes and phylogenetic analysis indicated a high degree of similarity to other insect CYP4 genes. Northern blotting analysis employing a fragment of $1200 \mathrm{bp}$ from the CYP4 gene as a probe indicated that the $C Y P 4$ gene was expressed in all developmental stages, but was expressed at highest levels in late instar larvae. Additionally, over-expression of CYP4 in $C$. tentans exposed to atrazine $(10 \mathrm{mg} / \mathrm{l})$ confirms the ability of atrazine to induce specific P450 genes and provides insight into potential consequences of atrazine exposure in aquatic organisms.
\end{abstract}

(C) 2007 Elsevier Inc. All rights reserved.

Keywords: Cytochrome P450; Atrazine; Induction; Chironomus tentans; Expression

\section{Introduction}

Cytochrome P450 (CYP)-dependent microsomal monoxygenases constitute the largest gene superfamily found in nature. The cytochrome P450 enzyme system has been detected in virtually all organisms examined from bacteria to mammals [1]. These enzymes constitute an extremely important metabolic system because of their involvement in regulating the titers of endogenous compounds such as hormones, fatty acids, and steroids. Additionally, this enzyme system plays a central role in the metabolism of xenobiotics such as drugs, pesticides, and plant toxins [1].

In insects, cytochrome P450 involvement in metabolism of insecticides results in either bio-activation or, more fre-

\footnotetext{
${ }^{*}$ Corresponding author. Fax: +14024728714.

E-mail address: bsiegfried1@unl.edu (B.D. Siegfried).
}

quently, in detoxification, the latter process being enhanced in many insect species that have developed metabolic resistance to insecticides. Additionally, cytochrome P450 is inducible through a mechanism shown to be largely controlled at the transcriptional level [2]. The net result of induction is often observed simply as an increase in enzyme activity. The ecological and physiological significance of induction is uncertain, although with insects, induction is thought to provide versatility in environmental adaptation [3] and may be a protective mechanism whereby the organism can detoxify lipophilic compounds that might otherwise accumulate to potentially toxic levels within cells [4].

The presence of an inducible cytochrome $\mathrm{P} 450$ system has been established in a number of different insects [5]. Given the importance of this enzyme system in both activation and detoxification of xenobiotics, induction may play a role in chemical interactions. Several recent studies have shown 
that in larvae of the midge, Chironomus tentans (Fabricius) (Diptera: Chironomidae), simultaneous exposure to the triazine herbicide, atrazine and selected organophosphate insecticides caused greater-than-additive toxicity [6-8]. Body residue analysis of midge larvae exposed in vivo to atrazine and chlorpyrifos mixtures indicated that chlorpyrifos was metabolized more rapidly in atrazine-treated midges compared to unexposed controls [7]. Importantly, in vivo metabolism of chlorpyrifos by treated and control midges indicated that the toxic metabolite, chlorpyrifos oxon, was formed more rapidly in atrazine-exposed midges [7].

These results strongly suggest that although atrazine is not acutely toxic, it may act as an inducer of cytochrome P450 activity. We have measured the effect of atrazine exposure on cytochrome P450-dependent monooxygenase activities including aldrin epoxidase [9] and $O$-demethylase [10] and observed increased activity in both assays as a result of atrazine exposure. A $45 \mathrm{kDa}$ protein of increased intensity was also observed after SDS-PAGE of microsomal protein which was similar in size to cytochrome P450 enzymes reported for other insects. Heme staining of SDS-PAGE gels and immunochemical studies using a Drosophila melanogaster anti-P450 polyclonal antiserum further supported the cytochrome P450 nature of this inducible $45 \mathrm{kDa}$ protein. A region of a cytochrome $\mathrm{P} 450$ family 4 gene was amplified using degenerate primers and sequenced from $C$. tentans larvae, and Northern blot analysis employing the CYP4 gene fragment as a probe indicated over-expression in larvae exposed to atrazine [10].

Atrazine is a herbicide that belongs to a group of pesticides used widely throughout the Midwestern U.S. and has been commonly reported as a contaminant of surface waters [11]. Although a biochemical understanding of atrazine induction of $\mathrm{P} 450$ enzymes in $C$. tentans and its potential to interact with other aquatic contaminants is emerging, specific $\mathrm{P} 450$ genes and gene products that are induced by atrazine have yet to be identified. In this manuscript, we describe the cloning, expression, and phylogenetic analysis of a novel atrazine-inducible family 4 cytochrome $\mathrm{P} 450$ from $C$. tentans.

\section{Materials and methods}

\subsection{Insect population}

A colony of $C$. tentans was obtained from Wichita State University, Department of Biological Sciences, and maintained according to U.S. EPA protocols [12] for static cultures with the slight modification that cultures were maintained with a mixture of developmental stages.

\subsection{Atrazine exposure}

Midge larvae were exposed to atrazine by maintaining groups of 50 third instars in 11 of moderately hard water in glass beakers at room temperature $\left(20-22{ }^{\circ} \mathrm{C}\right)$ and ambient lighting. Approximately $2 \mathrm{~cm}$ of sand was added to each beaker prior to introducing midges. An experiment consisted of control (without atrazine) and three experimental beakers with atrazine at $10 \mathrm{mg} / 1$. After acclimation of midges for $24 \mathrm{~h}, 1 \mathrm{ml}$ of technical grade atrazine ( $99 \%$ purity), purchased from Chem Service (West Chester, PA, USA) in ethyl acetate was added to the experimental beakers to achieve a concentration corresponding $10 \mathrm{mg} / \mathrm{l}$. Control treatments consisted of beakers treated with $1 \mathrm{ml}$ of ethyl acetate. After $90 \mathrm{~h}$ of exposure, the midges were collected from each beaker for RNA isolation.

\section{3. $R N A$ isolation}

Total RNA was isolated using TRIzol Reagent from Invitrogen Life Technologies (Carlsbad, CA). C. tentans first, second, and third instar larvae, pupae and adult tissue $(\sim 100 \mathrm{mg} / \mathrm{each})$ were ground in liquid $\mathrm{N}_{2}$ and processed with TRIzol to generate total RNA according to manufacturer instructions. The final RNA pellet was dissolved in $50 \mu \mathrm{l}$ of distilled, autoclaved water. Extracted RNA was diluted in Tris- $\mathrm{HCl}$ buffer $(5 \mathrm{mM}$, pH 8.0), quantified spectrophotometrically using the absorbance ratio $>1.8$ at $260 / 280 \mathrm{~nm}[13]$ and stored at $-80^{\circ} \mathrm{C}$ until further use.

\subsection{RACE PCR, cloning and sequence analysis}

Total RNA was used for RACE PCR (Rapid Amplification of cDNA ends) reactions. The SMART RACE cDNA Amplification kit (BD Biosciences, San Diego, CA) was used according to the manufacturer's instructions for both $5^{\prime}$ and $3^{\prime}$ RACE reactions. The PCRs were performed with oligonucleotide primers designed from the atrazine-inducible CYP4 fragment previously described from $C$. tentans [10]. The following $C Y P 4 G 33$ gene-specific primers were used for the initial $5^{\prime}$ RACE and $3^{\prime}$ RACE reactions, respectively: $5^{\prime}$-ATAATGATTGTTGTGCCTGCTGG-3' and $5^{\prime}$-TCCAGCAGGCACAACAATCATTA-3', both paired separately with the universal primer A mix (UPM) provided in the SMART RACE cDNA amplification kit. Following amplification, RACE products were separated on a $1 \%$ agarose gel. Products were excised from the gel and purified using a QIAquick gel extraction kit (QIAgen, Valencia, CA). Isolated fragments were cloned into the vector pCR2.1 TOPO (Invitrogen, Carlsbad, CA). Positive clones were sequenced at the Iowa State University DNA sequencing facility. By merging the overlapping sequences from the $3^{\prime}$ and $5^{\prime}$ reactions, a putative full-length cDNA was generated. Sequence analyses of gene fragments were repeated at least three times with different RNA preparations.

To confirm that the sequences generated by RACE PCR were from the same gene, nearly the full-length cDNA was amplified using gene-specific primers (Fig. 1) complementary to the $5^{\prime}$ - and $3^{\prime}$ ends of the cDNA sequence using first strand cDNA as template. 
gatttcagtttttcattcaattgatagtgataagtagtagttgaaatattttctcatcaaattaaggattaacataccaaca

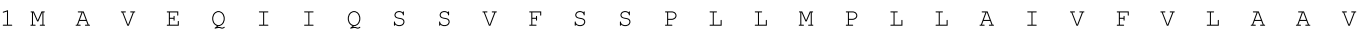

1 atggctgtggagcaaatcattcagagtagtgtgttctcatctccactactgatgcctctccttgcaattgttttcgttcttgctgctgtg F1

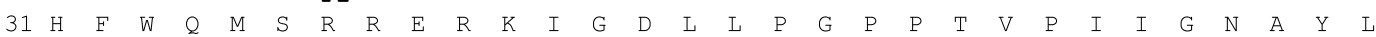

91 cacttttggcaaatgtcaagaagggagagaaaattggagatttacttccaggaccaccgacagttccaattattggaaacgcttattta

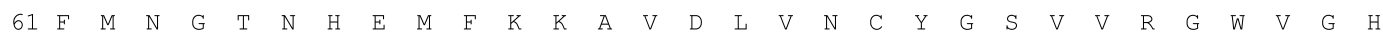

181 ttcatgaacggcacaaatcatgaaatgttcaaaaagccgtcgacctcgtcaactgctacggaagcgtcgttcgtggttgggtagggcac

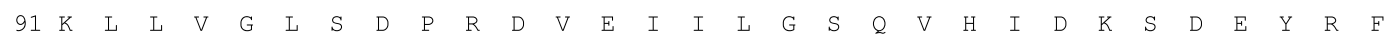

271 aaacttctcgtcggtctctcagatccacgtgatgttgaaatcatcttgggcagtcaagtccacattgataagtcagacgaatacagattc

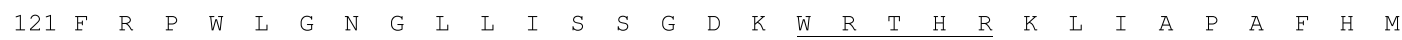

361 ttccgaccttggctcggtaatggcttgctaatttcaagtggagataaatggcgaacacatagaaaactcatcgccccagccttccacatg

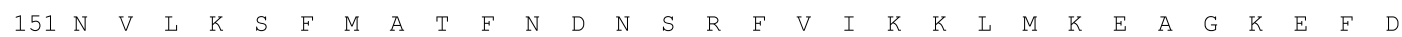

451 aatgttttgaagagcttcatggcaactttcaatgataacagtcgatttgtaatcaagaaattaatgaaggaagctggaaaggaattcgat

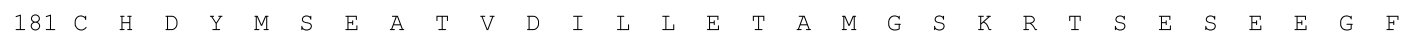

541 tgtcatgactatatgagtgaagctactgttgatattcttttggaaacagccatgggatcaaagagaacaagtgaaagtgaggaaggattc

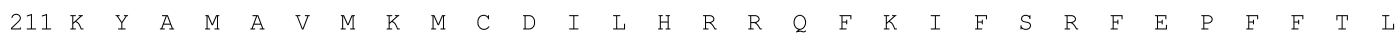

631 aagtatgcaatggctgttatgaaaatgtgcgacatcctccacagacgtcaattcaaaatcttctcaagattcgaaccattcttcaccttg

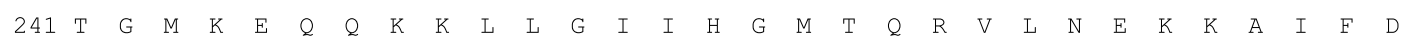

721 accggcatgaaggaacaacaaaaaaagcttttaggcatcattcatggtatgacacaacgggtactcaacgaaaagaaggcaatctttgat

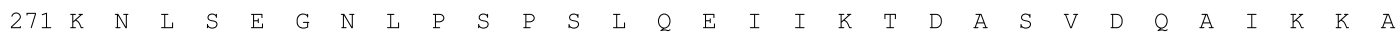

811 aagaatttatcagaaggtaacctcccatcaccatcacttcaagaaattattaaaactgatgcatcagttgatcaagcaattaagaaagca

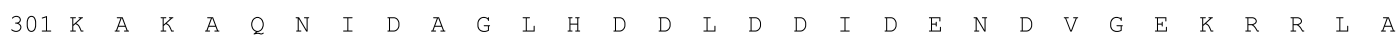

901 aaggcaaaggcacaaaacattgatgccggtcttcatgatgatcttgatgatattgatgaaaatgatgttggtgaaaagagacgattggca

$\begin{array}{lllllllllllllllllllllllllllllll}331 & F & L & D & L & M & I & E & T & S & H & Y & N & P & Q & Q & L & S & Q & E & E & I & K & Q & Q & V & D & T & I & M & F\end{array}$

991 ttccttgatttgatgattgaaacttcacattataatccacaacaattgtctcaggaggaaattaaacaacaagtcgacacaattatgttt

$\begin{array}{lllllllllllllllllllllllllllllllllllllllll}361 & E & G & H & D & T & T & A & A & G & S & S & F & T & L & C & M & L & G & C & H & P & D & I & Q & E & K & V & Y & Q & E\end{array}$

1081 gaaggacatgacacaactgctgctggatctagttttacattgtgtatgctaggatgtcatccggatatccaagaaaagtttatcaggaa

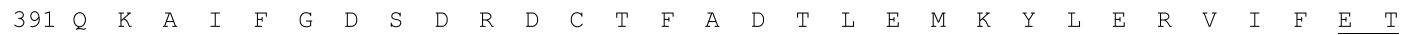

1171 caaaagcaatttttggtgattcagatcgagactgtacattcgcagatacattggagatgaaatatttggaaagagtcatttttgaaaca

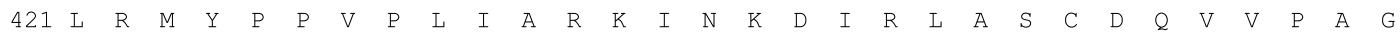

1261 ttgaggatgtacccaccagttccacttattgccagaaaatcaacaaagacatccgtcttgcatcatgtgatcaagttgttccagcaggc

$\begin{array}{lllllllllllllllllllllllllllllllllll}451 & \mathrm{~T} & \mathrm{~T} & \mathrm{I} & \mathrm{I} & \mathrm{I} & \mathrm{A} & \mathrm{T} & \mathrm{V} & \mathrm{K} & \mathrm{I} & \mathrm{H} & \mathrm{R} & \mathrm{R} & \mathrm{P} & \mathrm{D} & \mathrm{I} & \mathrm{Y} & \mathrm{P} & \mathrm{N} & \mathrm{P} & \mathrm{D} & \mathrm{K} & \mathrm{F} & \mathrm{D} & \mathrm{P} & \mathrm{D} & \mathrm{N} & \mathrm{F} & \mathrm{L} & \mathrm{P}\end{array}$

1351 acaacaatcattattgctacagttaaattcatcgacgacctgatatctatccaacccagacaaatttgatcctgacaactttttaccc

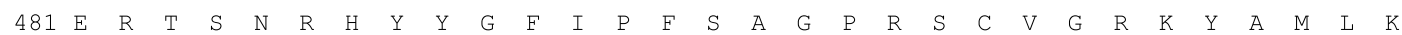

1441 gaaagaacatcaaacagacattattatggcttcattccattcagtgctggaccacgatcatgtgttggacgcaaatacgcaatgttgaag

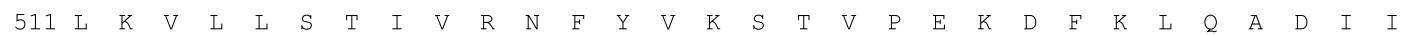

1531 ttgaaagttcttctcagtacaattgtgaggaacttctacgttaagagtacagttccagagaaagatttcaagcttcaagctgatattatc

$\begin{array}{llllllllllllllllllllllll}541 & \text { L } & K & R & T & D & G & F & R & I & K & L & E & P & R & K & T & K & A & N & *\end{array}$

1621 ttgaagagaactgatggattcagaattaaattggaaccaagaagaccaaagctaactaaattgacaaatattaatattaatagcaaatg R2
\end{abstract}

1711 acttatgatgaccttgaaaaaaaaaaaaaaaaaaaaaaaaaaaaaaa

Fig. 1. Full length cDNA sequence of CYP4G33 (Accession No. AY880065) and the conceptual translation of this gene. Both amino acids and nucleotides are numbered on the left. Gene specific primers used to confirm sequences from RACE PCRs are in bold and amino acids in conserved regions within P450 underlined. Both start codon (atg) and stop codon (taa) are double underlined.

\subsection{Sequence and phylogenetic analyses}

Assembly of sequence fragments, sequence confirmation and amino acid translations were conducted using Vector NTI ContigExpress (Invitrogen, Carlsbad, CA). Sequence alignment of the deduced $C$. tentans CYP4G33 protein with other CYP4 proteins was performed using ClustalW [13] within the MEGA3.1 program [14] with default parameters. Computer-assisted phylogenetic analysis was conducted with the MEGA3.1 program [14], using the bootstrapping $\mathrm{N}-\mathrm{J}$ tree (1000 trials) with the Jones-Tay-
lor-Thornton (JTT) matrix, pairwise deletion of gaps and missing data, and a uniform rate of evolution. A consensus tree was obtained which shows all the branches that are supported at the default cutoff bootstrap confidence limits $(B C L)$ of $\geqslant 50 \%$.

\subsection{Northern blotting}

A $1.2 \mathrm{~kb}$ fragment corresponding to the cytochrome P450 family 4 gene isolated from C. tentans was labeled by direct dioxigenin (DIG)-labeling of DNA fragments 
generated by PCR amplification using the PCR DIG Probe Synthesis Kit (Roche Biochemical; Mannheim, Germany) according to the manufacturer's instructions. Northern blot- ting was performed with RNA fixed to nylon membranes (Zeta-Probe; Bio-Rad, Hercules, CA) by capillary transfer following denaturing formaldehyde agarose electrophoresis

Table 1

Percentage of amino acid identity among 24 insect CYP4 full genes with atrazine inducible CYP4G33 from C. tentans

\begin{tabular}{llll}
\hline Insect species & Family & \% Identity & Source \\
\hline Aedes aegypti & Similar to CYP4G17 & 64 & EAT39885 \\
Anopheles gambiae & CYP4G17 & 62 & a \\
Apis mellifera & CYP4G11 & 58 & ABB36785 \\
Bombyx mori & CYP4G25 & 58 & ABF51415 \\
Leptinotarsa decemlineata & CYP4G29 & 58 & AAZ94273 \\
Tribolium castaneum & Similar to CYP4G15 & 57 & XP973423 \\
Aedes aegypti & Similar to CYP4G16 & 56 & EAT44585 \\
Anopheles gambiae & CYP4G16 & 56 & a \\
Antheraea yamamai & CYP4G25 & 56 & BAD81026 \\
Ips paraconfusus & CYP4G27 & 55 & ABF06553 \\
Tribolium castaneum & Similar to CYP4G15 isof-1 & 55 & XP966683 \\
Blatella germanica & CYP4G19 & 54 & AAO20251 \\
Drosophila melanogaster & CYP4G1 & 54 & AAF45503 \\
Drosophila melanogaster & CYP4G15 & 52 & AAF76522 \\
Musca domestica & CYP4G13 & 50 & AAK40120 \\
Blaberus discoidalis & CYP4C1 & 38 & AAA27819 \\
Drosophila melanogaster & CYP4C3 & 36 & AAF57098 \\
Coptotermes acinaciformis & CYP4U1 & 35 & AAC03111 \\
Mamestra brassicae & CYP4L4 & 34 & AAL48300 \\
Manduca sexta & CYP4M2 & 34 & AAC21661 \\
Diabrotica virgifera virgifera & CYP4AJ1 & 31 & AAF67724 \\
\hline
\end{tabular}

${ }^{a}$ http://drnelson.utmem.edu/anopheles.fasta.html.

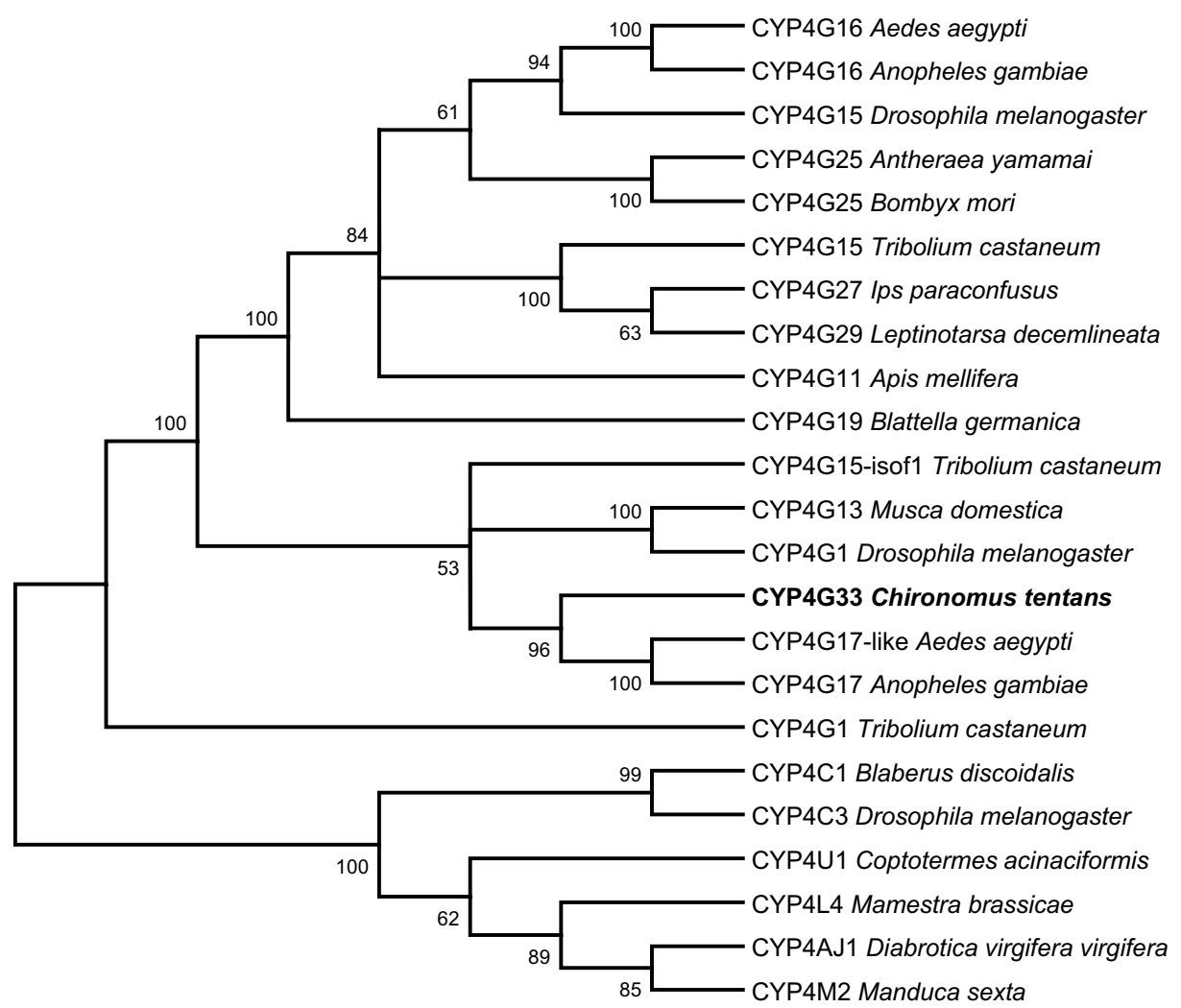

Fig. 2. Phylogenetic tree of aligned Chironomus tentans CYP4G33 with other CYP4 sequences from different insect orders. Alignment was performed with ClustalW within the MEGA 3.1 package. See Section 2 for details of analysis. The numbers close to the nodes correspond to the bootstrap values. 
[15]. Hybridization occurred overnight at $42{ }^{\circ} \mathrm{C}$ followed by three washes at room temperature with a final wash at $68{ }^{\circ} \mathrm{C}$ under mild agitation. Luminescent detection was accomplished using the DIG High Prime Detection Kit (Roche, Mannheim, Germany) following the manufacture's instructions. A control probe for an actin gene was amplified from a $C$. tentans cDNA mix using the forward primer, 5'-TCAGGGTGTGATGGTAGG-3' and reverse primer, 5'-CTCTTTCTGCTGTGGTGGTG-3' to generate a 560 bp fragment. RNA used in blotting experiments was extracted as described previously, quantified spectrophotometrically and standardized loadings were confirmed by hybridization with an actin probe specific for $C$. tentans (Accession No. DQ176317).

\section{Results and discussion}

\subsection{Cloning and sequencing}

CYP4 gene fragments corresponding to the $3^{\prime}$ and $5^{\prime}$ cDNA ends were successfully cloned, and the overlapping fragments generated an open reading frame of $1678 \mathrm{bp}$ with a deduced protein of 559 amino acids (AA) and a predicted molecular mass of $63.8 \mathrm{kDa}$ (Fig. 1). Gene-specific primers that flanked most of the ORF resulted in a fragment of the expected size and sequence. The full-length cDNA of this CYP4 gene has been named CYP4G33 by the P450 Nomenclature Committee (Accession No. AY880065). CYP4 genes from several different insect orders share a high degree of sequence similarity with CYP4G33 (Table 1) and support its assignment to the CYP4 P450 family. The highest percent AA identities (Table 1) were with CYP4G17 (64\%) from Aedes aegypti and CYP4G17 (62\%) from Anopheles gambiae, and all three genes appear to be closely related (Fig. 2).

The deduced AA sequence of CYP4G33 contains important domains that are conserved among microsomal P450s (underlined AAs, Figs. 1 and 3). The P450 protein signa- ture motif in the heme binding region, FxxGxRxCxG [16] is present at AA residues 494-503 (Fig.1). The deduced AA sequence also shares a number of common characteristics with other members of the P450 superfamily, such as the charge pair consensus (ExxR) [17] within the K-helix, the consensus (WxxxR) in the C-helix and the consensus sequence (A/G/E)GxxT) (Figs. 1 and 3) [18,19].

A partial AA sequence alignment in regions conserved among P450 enzymes indicates a highly conserved AA sequence that appears as 12 residues (QVDTIMFEGHDTT) (354-361). This conserved region is in contrast to the 13-residue motif (EVDTFMFEGHDTT) previously reported as invariant among CYP4 family members $[20,21]$. The differences at positions 354 (E/Q), 356 (D/ $\mathrm{G} / \mathrm{N})$, and position $358(\mathrm{~F} / \mathrm{I})$ indicate that this region is less conserved than previously thought.

\subsection{Determination of CYP4 atrazine induction by Northern blotting}

Following atrazine exposure for $90 \mathrm{~h}$ at $10 \mathrm{mg} / 1, \mathrm{mRNA}$ was isolated from exposed and un-exposed third instar larvae from $C$. tentans. A single 695 bp mRNA band hybridized with the actin probe (control) and a $1.9 \mathrm{~kb}$ mRNA

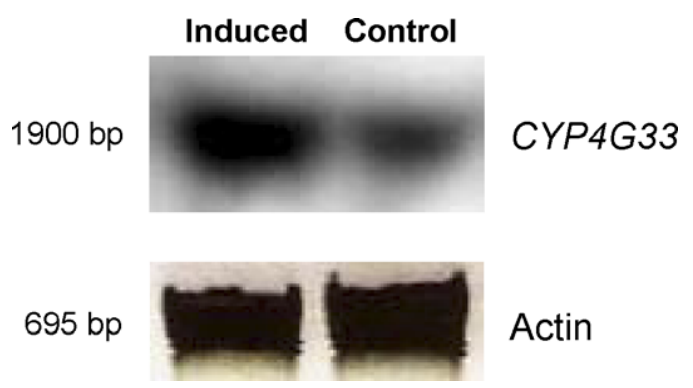

Fig. 4. Northern analysis of $C$. tentans CYP4 expression in induced (exposed to $10 \mathrm{mg} / \mathrm{l}$ atrazine in solution for $90 \mathrm{~h}$ ) and unexposed $3 \mathrm{rd}$ instars in comparison with $C$. tentans actin expression in control and atrazine-exposed 3rd instar larvae.

$\begin{array}{ll}\text { Chironomus tentans } & \text { CYP4G33 } \\ \text { Spodoptera litura } & \text { CYP4G32 } \\ \text { Spodoptera litura } & \text { CYP4G31 } \\ \text { Spodoptera litura } & \text { CYP4G30 } \\ \text { Leptinotarsa decemlineata } & \text { CYP4G29 } \\ \text { Antheraea yamamai } & \text { CYP4G25 } \\ \text { Bombyx mori } & \text { CYP4G25 } \\ \text { Anopheles funestus } & \text { CYP4G21 } \\ \text { Blatella germanica } & \text { CYP4G19 } \\ \text { Anopheles gambiae } & \text { CYP4G17 } \\ \text { Aedes aegypti } & \text { CYP4G17 } \\ \text { Drosophila melanogaster } & \text { CYP4G15 } \\ \text { Tribolium castaneum } & \text { CYP4G15 } \\ \text { Musca domestica } & \text { CYP4G13 } \\ \text { Apis mellifera } & \text { CYP4G11 } \\ \text { Solenopis invicta } & \text { CYP4AB1 } \\ \text { Blaberus discoidalis } & \text { CYP4C1 } \\ \text { Helicoverpa zea } & \text { CYP4M6 } \\ \text { Conserved AA } & \end{array}$

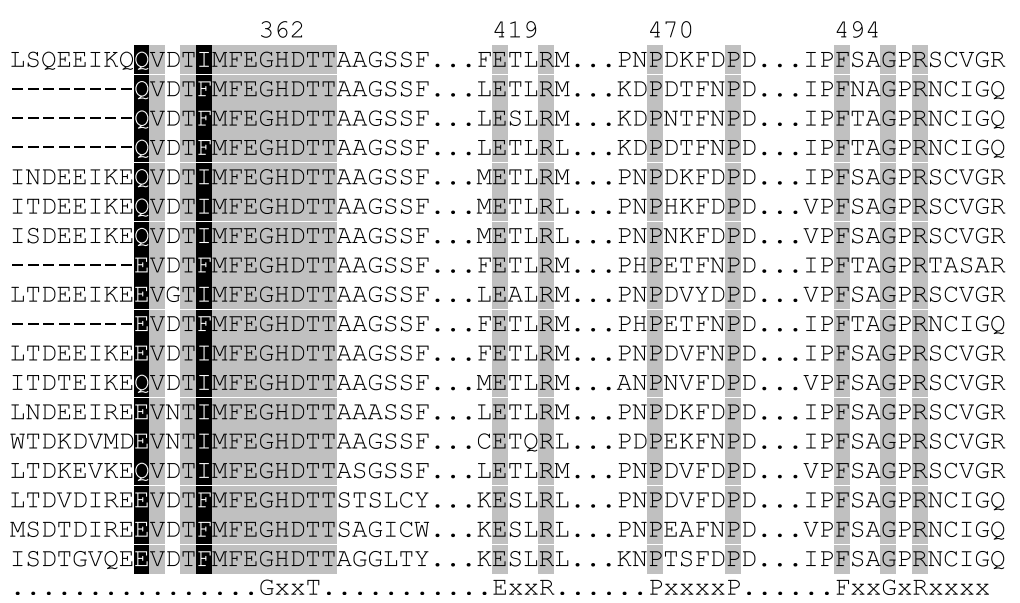

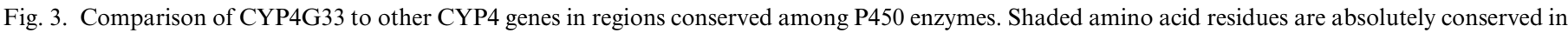

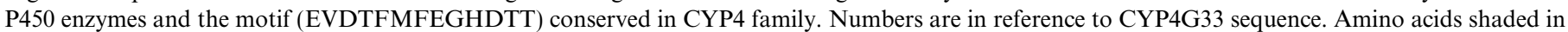
black are those that vary among CYP4 P450s. 


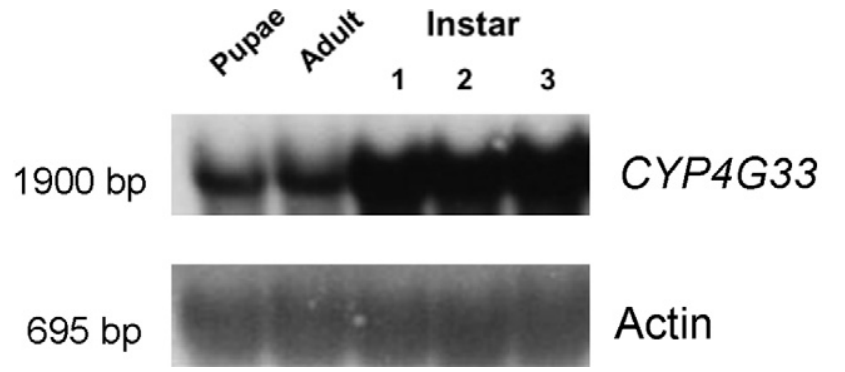

Fig. 5. Northern analysis of C. tentans CYP4G33 expression in different developmental stages in comparison with the $C$. tentans actin gene.

band hybridized with the CYP4G33 probe (Fig. 4). The signal for the CYP4 gene was more intense for atrazine exposed relative to unexposed midges confirming that cytochrome P450 family 4 gene expression was induced by atrazine (Fig. 4). Previous studies employing a partial family 4 sequence as a probe indicated that two P450 family 4 genes were induced by atrazine [10]. This could be a result of multiple P450 family 4 genes induced by atrazine or a single gene with an alternative splicing [19]. The longer probe used in the present study is likely to have provided a higher degree of specificity and could explain the detection of a single band.

\subsection{Determination of CYP4 expression levels by Northern blotting}

CYP4G33 expression was compared among the different developmental stages of $C$. tentans. A single $695 \mathrm{bp}$ mRNA band hybridized with the actin probe (control) and a $1.9 \mathrm{~kb}$ mRNA band hybridized with the CYP4 probe in the Northern blot (Fig 5). A signal of the CYP4 gene was highest in all larval stages with much lower expression in adults and pupae (Fig. 5).

Induction of cytochrome $\mathrm{P} 450$ by herbicides and the consequences to insecticide toxicity are not well documented. Kao et al. [22] have shown that incorporation of the herbicides atrazine and 2,4-D into the diet of southern armyworm (Spodoptera eridania) resulted in induction of both cytochrome P450 activity and total P450 content [22]. Additionally, atrazine has been shown to synergize the toxicity of a number of different insecticides in D. melanogaster [23], although the exact mechanism of this synergism has not been determined.

Insect CYP4 genes are suggested to be involved in toxin metabolism, and some CYP4 enzymes have been implicated in the metabolism of steroids and xenobiotics [24]. Family 4 cytochrome P450's exhibit a high degree of structural diversity and have been identified from numerous invertebrates, although for most of these enzymes a specific function has yet to be described [22].

Results from the present research are important because knowledge of the cytochrome P450 diversity in insects especially for those species that have potential to serve as bio-indicators, may provide important tools for future development of biochemical and molecular markers associated with adaptation and resistance to chemicals. Our data suggest that $C$. tentans CYP4G33 is a reliable marker for atrazine-exposure at $10 \mathrm{mg} / 1$ in this species and provide some evidence for a role of this protein in pesticide metabolism. Future research should test the reliability of this marker at lower more environmentally relevant concentrations. Given the large number of genes in the CYP superfamily, assigning even putative functions assists in clarifying the roles of specific proteins (e.g. CYP4G33) in cellular metabolism. Identification of a specific inducible cytochrome P450 will improve our understanding of the molecular and chemical basis of cytochrome P450 family 4 mediated detoxification of atrazine in aquatic organisms.

\section{Acknowledgments}

Terence Spence provided invaluable assistance with colony maintenance. Support for the project was obtained from a USDA National Research Initiative Grant \# 2003-35102-13545 to M.J. Lydy, K.Y. Zhu and B.D. Siegfried.

\section{References}

[1] J.G. Scott, Cytochromes P450 and insecticide resistance, Insect Biochem. Molec. Biol. 29 (1999) 757-777.

[2] Y. Batard, M. Schalk, M.A. Pierrel, A. Zimmerlin, F. Durst, D. WerckReichhart, Regulation of the cinnamate 4-hydroxylase (CYP73A1) in Jerusalem artichoke tubers in response to wounding and chemical treatments, Plant Physiol. 113 (1997) 951-959.

[3] L.C. Terriere, Induction of detoxication enzymes in insects, Ann. Rev. Entomol. 29 (1984) 71-88.

[4] J.P. Whitlock, M.S. Denison, Induction of cytochrome P450 enzymes that metabolize xenobiotics, in: P.R. Ortiz de Montellano (Ed.), Cytochrome P450, Plenum Press, New York, NY, 1995, pp. 367-390.

[5] S.Y. Fuchs, V.S. Spiegelman, G.A. Belitsky, Inducibility of various cytochrome-P450 isozymes by phenobarbital and some other xenobiotics in Drosophila melanogaster, Biochem. Pharmacol. 47 (1994) 1867-1873.

[6] P.A. PapeLindstrom, M.J. Lydy, Synergistic toxicity of atrazine and organophosphate insecticides contravenes the response addition mixture model, Environ. Toxicol. Chem. 16 (1997) 2415-2420.

[7] J.B. Belden, M.J. Lydy, Impact of atrazine on organophosphate insecticide toxicity, Environ. Toxicol. Chem. 19 (2000) 2266-2274.

[8] Y. Jin-Clark, M.J. Lydy, K.Y. Zhu, Effects of atrazine and cyanazine on chlorpyrifos toxicity in Chironomus tentans (Diptera: Chironomidae), Environ. Toxiol. Chem. 21 (2002) 598-603.

[9] F. Miota, B.D. Siegfried, M.E. Scharf, M.J. Lydy, Atrazine induction of cytochrome P450 in Chironomus tentans larvae, Chemosphere 40 (2000) 285-291.

[10] D.K. Londono, B.D. Siegfried, M.J. Lydy, Atrazine induction of a family 4 cytochrome P450 gene in Chironomus tentans (Diptera: Chironomidae), Chemosphere 56 (2004) 701-706.

[11] K.R. Solomon, D.B. Baker, R.P. Richards, D.R. Dixon, S.J. Klaine, T.W. LaPoint, R.J. Kendall, C.P. Weisskopf, J.M. Giddings, J.P. Giesy, L.W. Hall, W.M. Williams, Ecological risk assessment of atrazine in North American surface waters, Environ. Toxicol. Chem. 15 (1996) 31-74.

[12] [USEPA] U.S. Environmental Protection Agency, Methods for measuring the acute toxicity of effluents and receiving waters to freshwater and marine organisms, EPA 821-R-02-012, Washington, D.C., USA:USEPA, 2002. 
[13] J.D. Thompson, D.G. Higgins, T.J. Gibson, CLUSTAL W: improving the sensitivity of progressive multiple sequence alignment through sequence weighting, position-specific gap penalties and weight matrix choice, Nucleic Acids Res. 22 (1994) 4673-4680.

[14] S. Kumar, K. Tamura, M. Nei, MEGA3: Integrated software for molecular evolutionary genetics analysis and sequence alignment, Brief Bioinform. 5 (2004) 150-163.

[15] J. Sambrook, E.F. Fritsch, T. Maniatis, Molecular Cloning: A Laboratory Manual, Cold Spring Harbor Laboratory Press, Cold Spring Harbor, NY, 1989.

[16] S. Kasai, I.S. Weerashinghe, T. Shono, M. Yamakawa, Molecular cloning, nucleotide sequence and gene expression of a cytochrome P450 (CYP6F1) from the pyrethroid-resistant mosquito, Culex quinquefasciatus Say, Insect Biochem. Molec. Biol. 30 (2000) 163171.

[17] S. Grahamlorence, B. Amarneh, R.E. White, J.A. Peterson, E.R. Simpson, A 3-dimensional model of aromatase cytochrome-P450, Protein Sci. 4 (1995) 1065-1080.

[18] D.R. Nelson, Metazoan cytochrome P450 evolution, Comp. Biochem. Physiol. C: Pharmacol. Toxicol. 121 (1998) 15-22.
[19] Z. Wen, J.G. Scott, Cloning of two novel P450 cDNAs from German cockroaches, Blattella germanica (L.): CYP6K1 and CYP6J1, Insect Molec. Biol. 10 (2001) 131-137.

[20] N.N. Liu, L. Zhang, CYP4AB1, CYP4AB2, and Gp-9 gene overexpression associated with workers of the red imported fire ant, Solenopsis invicta Buren, Gene 327 (2004) 81-87.

[21] H. He, A.C. Chen, R.B. Davey, G.W. Ivie, Molecular cloning and nucleotide sequence of a new P450 gene, CYP319A1, from the cattle tick, Boophilus microplus, Insect Biochem. Molec. Biol. 32 (2002) 303309

[22] L.M. Kao, C.F. Wilkinson, L.B. Brattsten, In-vivo effects of 2,4-D and atrazine on cytochrome P-450 and insecticide toxicity in southern armyworm (Spodoptera eridania) larvae, Pesticide Sci. 45 (1995) 331334.

[23] E.P. Lichtenstein, T.T. Liang, B.N. Anderegg, Synergism of insecticides by herbicides, Science 181 (1973) 847-849.

[24] K.F. Rewitz, C. Kjellerup, A. Jorgensen, C. Petersen, O. Andersen, Identification of two Nereis virens (Annelida: Polychaeta) cytochromes P450 and induction by xenobiotics, Comp. Biochem. Physiol. C: Pharmacol. Toxicol. 138 (2004) 89-96. 